\title{
Evaluate the Effectiveness of Job Rotation System and its Impact on Employees' Readiness for Job Rotation (Case Study of: Maskan Bank branches in the city of Tabriz)
}

\author{
Farshid Ali-Mohammadi6, Mojtaba Ramezani7
}

\begin{abstract}
The aim of this study is to evaluate the effectiveness of job rotation system and its impact on employees' readiness for organizational change in the Maskan bank branches in the city of Tabriz. For this purpose, the effectiveness of job rotation system is defined based on the theory of Nana Edom and employees' readiness for organizational change based on the theory of Dunham et al., as three main hypotheses have been developed. The statistical population includes employees of Maskan bank branches in the city of Tabriz, equal to 485 people. The sample estimated 214 employees by using the Cochrane formula and selection performed by stratified random sampling method. Data collection tool was two questionnaires: the effectiveness of job rotation system referred to Nana Edom and employees' readiness for organizational change by Dunham et al. After ensuring the validity and reliability, the questionnaire distributed among them. For statistical data analysis, descriptive and inferential statistical methods were used. Thus, for classifying, summarizing and describing statistical data, we used descriptive statistics methods, and to test hypotheses, $t$-test, Kolmogorov-Smirnov, $r$ Pearson and Spearman regression in SPSS software were used. The results show that the effectiveness of the job rotation system and employees' readiness for organizational change in the Maskan bank branches in the city of Tabriz level is higher than average. The results of this study show that the effectiveness of the job rotation system on employees' readiness for organizational change in the Maskan bank branches in the city of Tabriz is influential.
\end{abstract}

KEY WORDS: Job Rotation, Readiness For Organizational Change, Organizational Change

JEL: J24, M51, L23

UDC: 005.961:005.562

COBISS.SR-ID 238307596

\footnotetext{
${ }^{6}$ Department of Management, Tabriz Branch, Islamic Azad University, Tabriz, Iran

${ }^{7}$ Department of Management, Tabriz Branch, Islamic Azad University, Tabriz, Iran
} 


\section{INTRODUCTION}

Job rotation is planned replacement of staff in jobs and in different time periods with the aim of gaining skills and job autonomy, motivation, and productivity (Saravani,Abbasi, 2013). Job rotation is an interesting mechanism for employees to work in different positions and jobs as possible. And as a result it leads to learning and working in various professions to learn one's appropriate job (Ortega, 2001; Kuijer, de Vries, van der Beek, van Dien, Frings-Dresen, 2004), defined job rotation as: it happens regularly, alternatively between different jobs in an organization based on a plan, or alternatively based on individual needs of workers (Coyne, 2011). Job rotation is a horizontal displacement of workers in different stations so that each workstation requires different skills and responsibilities (Dari et al., 2012). Job rotation is including job design strategies, which is used to enhance staff motivation at work or repetitive tasks (Ayough et al., 2009). John Sullivan, (2008) presents this definition: job rotation is a systematic displacement from a job to another job or from project to another project within an organization, as one of the ways to achieve different objectives of human resources.

Changes in the organization affect employees' attitudes, behaviors and beliefs, because it is the transition from a known state into unknown state. This particular situation can bring uncertainty, stress and anxiety on staff. Therefore, its scope, involved researchers on how employees within the organization can be confronted with this issue, so they actively accept the agreement and be involved in the process of change programs (Shah, 2009).

Currently, organizations are all faced with great changes that their various stakeholders are waiting for. Sometimes, to develop organizational competencies, we seek for change. Sometimes we want to build a creative and joyful environment to attract or retain best people. Sometimes, change is for the survival of the organization. In most organizations, all three issues are raised (Paknejad et al., 2010). According to change experts, employees' readiness for change is the main prerequisite for the successful implementation of change, but the ability of organizations to create consistency and adaptation to the changes is unclear and about 70 percent of change management programs fail (Maleki et al., 2012).

Many factors are involved in the effectiveness of implemented changes such as changes in organizations. One of these factors is the readiness for change. Readiness is reflected in beliefs, attitudes and intentions regarding the extent of required changes and organization's capacity for successful implementation of these changes (Susanto, 2008).

Most experts believe that the success of organizations depends on satisfied, motivated and creative employees trying to achieve the goals of the organization. In this case, managers will be able to bring the capabilities of people from potentiality to actuality. One of the strategic tasks of organizational management is to utilize special techniques, to create suitable environment to flourish the talents and abilities of employees. Studies have shown that when senior management accepts change, willingness of low and middle managers should be considered in implementation of change and be convinced about the need for change. Many of the barriers to change, are rooted in readiness to accept organizational transformation. Psychologically these obstacles, such as administrative barriers, can be described by insecurity and fear of negative consequences for individuals. In dynamic environments, organizations need to implement continuous change in strategy, structure, process, and their culture (Rangriz, Moradi, 2014).

Many factors affect the readiness of staff and organizational change associated with it. That in the present study is designed to evaluate the effectiveness of job rotation and its impact on the readiness of employees to organizational changes in the Industry, Mine and Trade East Azarbaijan be examined. Job rotation including management measures in the area of human resource management. In which the displacement of workers in different occupations are provided with various incentives and contingency occurs (Culture and others, 1391). 
Job rotation is considered as a method of designing jobs that employees learn job skills in different sections, and fatigue caused by repetitive job tasks are solved with a change in duties (Delpasand et al., 2010).

Job rotation is a great tool to enhance staff motivation, commitment and participation in the work, which is also important in an effective and integrated performance of organization. Job rotation is accepted as an effective way to develop skills and motivation of the employees. Job rotation is a job design process that is widely used in many organizations at different levels of the organizational hierarchy. Job rotation is the result of effort and determination and implementation of human structure with technological processes. Job rotation is an important process in human resource capital development policies, which potentially plays a role in improving job satisfaction and enhances the capabilities of employees (Wageeh, 2014).

Job rotation is appropriate for training employees in jobs with similar content, methods and skills. This approach should be used when the temporary change of jobs for two or more employees do not cause chaos, lack of organizational effectiveness, and losses to organizational units. Thus, job rotation will bring many advantages for organizations (Abili, Khodayari, 2002).

\section{Hypotheses}

1. Effectiveness of job rotation system for employees of Maskan bank branches in Tabriz is higher than average.

2. Employees' readiness for organizational change in Maskan bank branches in Tabriz is higher than average.

3. Effectiveness of the job rotation system on employees' readiness for organizational change in the Maskan bank branches in the city of Tabriz is influential.

\section{Operating Model of Job Rotation System Effectiveness}

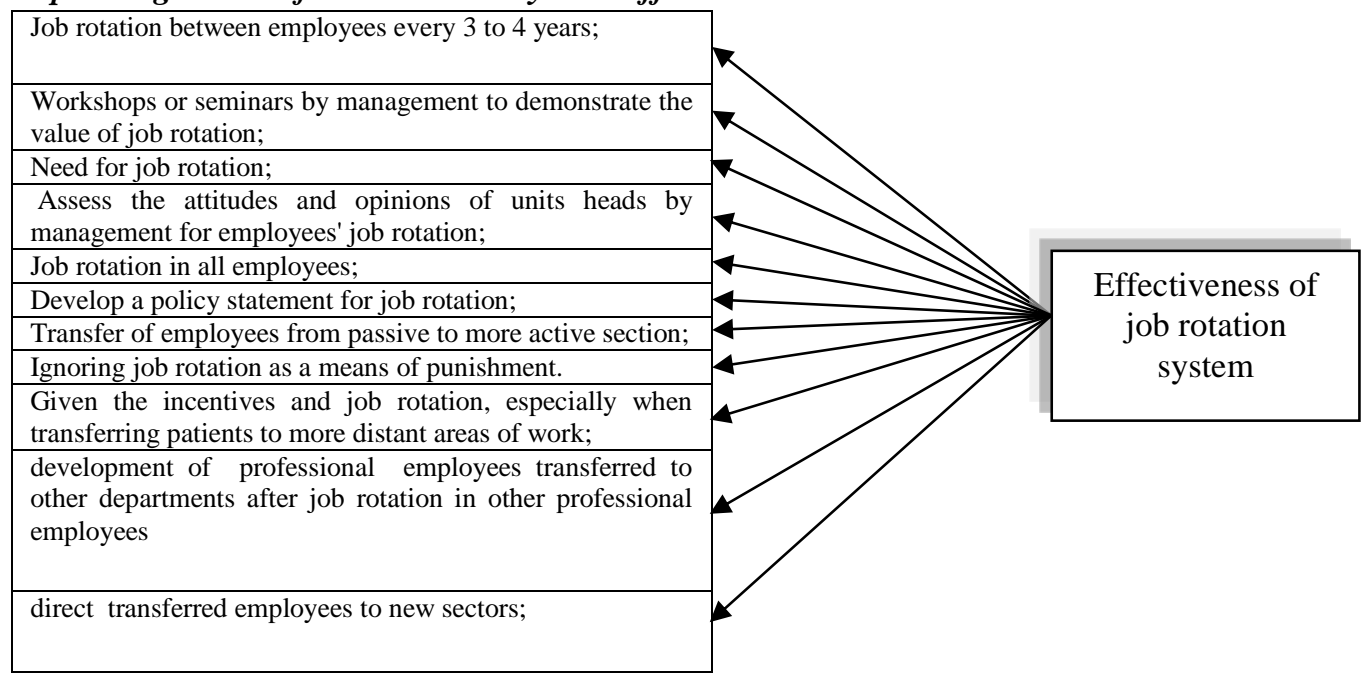

Figure 1: Operating Model of Job Rotation System Effectiveness 


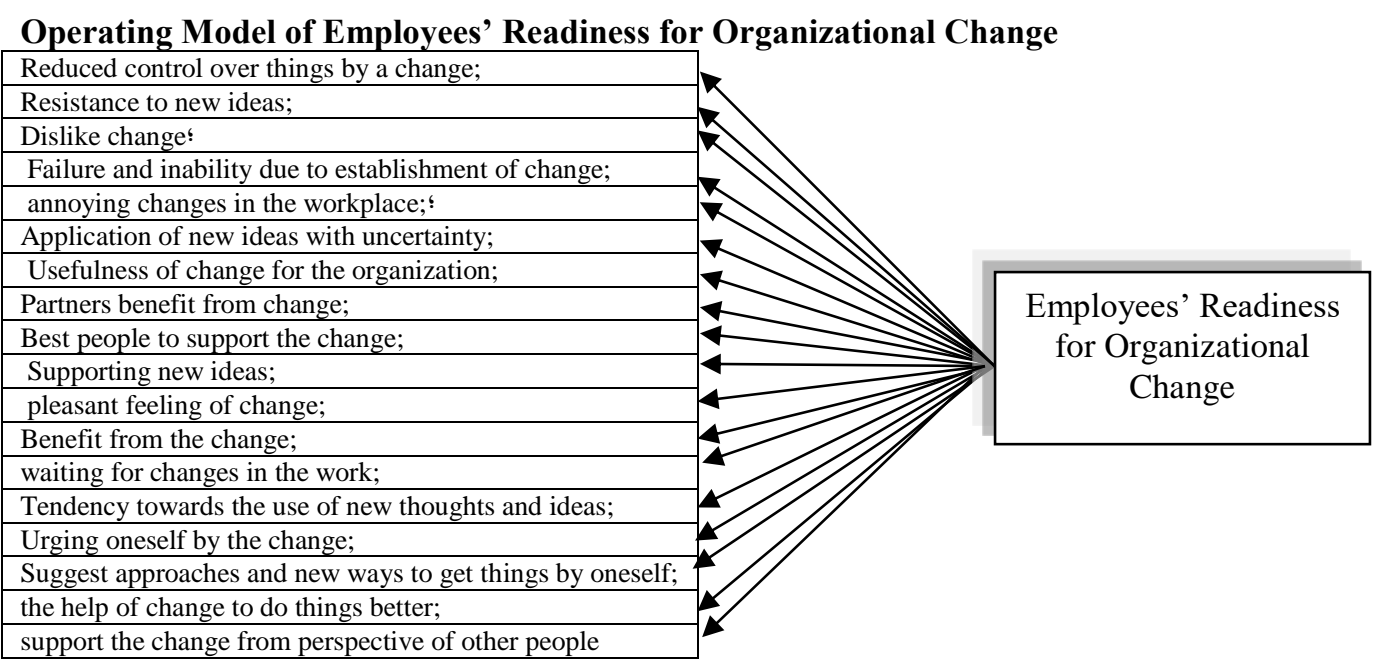

Figure 2: Operating Model of Employees' Readiness for Organizational Change

\section{RESEARCH METHODOLOGY}

The present study is applicable in terms of objective; and the descriptive and correlation methods have been used in this study.

The population of this study consists of all formal and contracted personnel of Maskan Bank city branches in Tabriz, which is equal to 485 people.

In order to determine the sample size, Cochrane formula is used. In this formula at $05 / 0$ error, the sample size is 214 people.

In order to determine the sample size, Cochrane formula is used as follows:

$$
n=\frac{\frac{t^{2} p q}{d^{2}}}{1+\frac{1}{N}\left(\frac{t^{2} p q}{d^{2}}-1\right)}
$$

Where:

$\mathrm{N}=$ population size, $\mathrm{N}=485$

$\mathrm{P}=$ probability of having a desired trait, $\mathrm{P}=0 / 5$

$\mathrm{q}=$ probability of lack of desired trait, $\mathrm{q}=0 / 5$

$\mathrm{d}=$ probability of accuracy (half of $\mathrm{CI}$ ), $\mathrm{d}=0 / 05$

$\mathrm{t}=$ degrees or confidence coefficient of $95 \%, \mathrm{t}=1 / 96$

$$
\begin{aligned}
& n=\frac{\frac{1 / 96^{2} \times 0 / 5 \times 0 / 5}{0 / 05^{2}}}{1+\frac{1}{485}\left(\frac{1 / 96^{2} \times 0 / 5 \times 0 / 5}{0 / 05^{2}}-1\right)} \\
& n=\frac{\frac{3 / 84 \times 0 / 5 \times 0 / 5}{0 / 0025}}{1+0 / 003125\left(\frac{0 / 96}{0 / 0025}-1\right)} \cong 171
\end{aligned}
$$


Since the population is homogeneous. In order to choose the sample from the population, simple random sampling method is used.

\section{Questionnaire}

To collect data from sample and to test the hypotheses, a questionnaire in accordance with research variables was used. The questionnaire consisted of two sets of questions. The first section is coded with alphabet letters, which is used in order to identify the characteristics of the sample in terms of gender, marital status, age, education, work experience; and the second section is provided in order to answer the research questions that categorized into two parts. The first part of the questionnaire refers to effectiveness of job rotation system which is referred to Nana Edom, consisting of 11 questions. Table 1 shows dimensions of effectiveness of job rotation system and the number of questions in each dimension in the questionnaire.

Table 1: Dimensions of effectiveness of job rotation system and the number of questions in each dimension in the questionnaire

\begin{tabular}{||c|c|c|c|}
\hline \multirow{2}{*}{ effectiveness of job rotation system } & Dimensions & $\begin{array}{c}\text { Number of } \\
\text { questions }\end{array}$ & $\begin{array}{c}\text { Questions } \\
\text { No. }\end{array}$ \\
\cline { 2 - 4 } & job rotation & 11 & $11-1$ \\
\hline \multicolumn{2}{|c|}{$\begin{array}{c}\text { total number of questions for } \\
\text { effectiveness of job rotation system }\end{array}$} & 11 & \\
\hline
\end{tabular}

The second part of the questions are about employees' readiness for organizational change, which is based on the dimensions introduced by Dunham et al. it consists of 18 questions. Table 2 shows the dimensions of employees' readiness for organizational change and number of questions in each dimension.

Table 2: The dimensions of employees' readiness for organizational change and number of questions in each dimension

\begin{tabular}{|c|c|c|c|}
\hline \multirow{4}{*}{$\begin{array}{r}\text { employees' readiness for organizational } \\
\text { change }\end{array}$} & Dimensions & $\begin{array}{c}\text { Number of } \\
\text { questions }\end{array}$ & $\begin{array}{c}\text { Questions } \\
\text { No. }\end{array}$ \\
\hline & Cognitive & 6 & $6-1$ \\
\hline & Emotional & 6 & $12-7$ \\
\hline & Behavioral & 6 & $18-13$ \\
\hline \multicolumn{2}{|c|}{$\begin{array}{r}\text { total number of questions on employees' readiness for } \\
\text { organizational change }\end{array}$} & 18 & \\
\hline
\end{tabular}

\section{Validity and reliability of job rotation questionnaire}

Reliability of "job rotation" questionnaire by Delpasand et al. (2010), has been obtained through Cronbach's alpha test (Alpha coefficient is between zero and one. One is full reliability and Cronbach's alpha coefficient of zero means lack of reliability. If alpha coefficient is higher than 0.6 , it can be concluded that high internal consistency exists in questions), which can be seen in the table below.

Table 3: Cronbach's alpha coefficient in "job rotation" questionnaire

\begin{tabular}{|c|c|}
\hline Variable & Cronbach's alpha coefficient \\
\hline job rotation & $0 / 78$ \\
\hline
\end{tabular}


Validity and reliability of employees' readiness for organizational change questionnaire

In their study, Dunham et al. (1989) approved validity and reliability of the questionnaire. Reliability alpha of the questionnaire obtained 0/88 (Paknejad et al., 2010, 157). Rashidi (2004) reported the reliability of the questionnaire by using Cronbach's alpha was $0 / 87$ and the validity was between $0 / 72$ to $0 / 82$ for the total attitude toward organizational change that showed acceptable reliability and validity of the questionnaire. Paknejad et al. (2010), in their research on trend towards change, obtained the Cronbach's alpha equal to $0 / 84$. Thus all the obtained coefficients, indicate the validity of these questionnaires. The Cronbach's alpha test of the questionnaire is presented in the following table.

Table 4: Cronbach's alpha coefficient in "employees' readiness for organizational change "questionnaire

\begin{tabular}{||l|c|}
\hline \hline Variable & Cronbach's alpha coefficient \\
\hline employees' readiness for organizational change & $0 / 88$ \\
\hline
\end{tabular}

\section{Statistical Descriptions}

According to obtained information: the sample encompasses 0/84 male and 0/16 females, of which 0/14 are single and 0/86 are married; 0/01 percent of the sample consists of individuals less than 25 years, 0/44 percent of the samples consisted of people between 25-35 years, 0/39 percent of the sample are between 36-45 years, $0 / 15$ percent of the sample are between $46-55$ years and $0 / 01$ percent of the sample are over 55 years. The samples consisted of $0 / 03$ percent with high school graduates, 0/10 percent with an associate degree, 0/69 with bachelor and 0/18 percent with master's degree and above. 0/06 percent of the sample have less than 5 years of service, $0 / 43$ percent have 5 to 10 years of service, $0 / 17$ percent have 11-15 years of service, 0/15 percent have 16-20 years of service, 0/12 percent have 21-25 years of service and 0/07 percent have more than 20 years of service.

\section{Data Normality Test}

Table 5: Kolmogorov-Smirnov test for normality of data

\begin{tabular}{|c|c|c|c|}
\hline Variables & $\begin{array}{c}\text { Number of } \\
\text { data }\end{array}$ & $\begin{array}{c}\text { Kolmogorov-Smirnov } \\
\text { statistic }\end{array}$ & P value \\
\hline job rotation & 214 & $0 / 845$ & $0 / 089$ \\
\hline $\begin{array}{c}\text { employees' readiness for } \\
\text { organizational change }\end{array}$ & 214 & $0 / 826$ & $0 / 054$ \\
\hline
\end{tabular}

According to the results of Table 5, it is observed that the test statistic in both variables is greater than $0 / 05$. Thus, distribution of data is normal. Pearson $r$ test is used to test the hypotheses of variables.

\section{The first hypothesis test}

The obtained mean for the effectiveness of job rotation system in the Maskan bank branches in the city of Tabriz is equal to 3.02 .

Table 6: $t$-test for the effectiveness of job rotation

\begin{tabular}{|c|c|c|c|c|c|}
\hline Independent variable & (Mean) & (Std.) & $\mathrm{t}$ & (Sig.) error & result \\
\hline the effectiveness of job rotation system & $3 / 02$ & $1 / 18715$ & $2 / 953$ & $0 / 001$ & confirmed \\
\hline
\end{tabular}


Results of analysis show that due to the calculated $t$, which is greater than critical $t$ at error level of $0 / 05$ and the significant level is $0 / 001$. At confidence level of $95 \%$, it can be concluded that effectiveness of job rotation system among the employees is above average.

\section{The second hypothesis test}

The obtained mean for employees' readiness for organizational change in the Maskan bank branches in the city of Tabriz is equal to 5.17.

Table 7: $t$-test for the employees' readiness for organizational change

\begin{tabular}{|c|c|c|c|c|c|}
\hline dependent variable & (Mean) & (Std.) & t & (Sig.) error & result \\
\hline $\begin{array}{c}\text { employees' readiness for } \\
\text { organizational change }\end{array}$ & $5 / 17$ & $1 / 45031$ & $28 / 511$ & $0 / 000$ & confirmed \\
\hline
\end{tabular}

Results of analysis show that due to the calculated $\mathrm{t}$, which is greater than critical $\mathrm{t}$ at error level of $0 / 05$ and the significant level is $0 / 000$. At confidence level of $95 \%$, it can be concluded that employees' readiness for organizational change is above average.

\section{The third hypothesis test}

Table 7: Pearson for the third hypothesis

\begin{tabular}{||c|c|c|c|c|}
\hline Independent variable & Dependent variable & (r) & (P-Value) & result \\
\hline $\begin{array}{c}\text { the effectiveness of job } \\
\text { rotation system }\end{array}$ & $\begin{array}{c}\text { employees' readiness for } \\
\text { organizational change }\end{array}$ & $0 / 302$ & $0 / 000$ & significant \\
\hline
\end{tabular}

According to the results obtained from Table 7, the Pearson correlation coefficient between the components of job rotation and employees' readiness for organizational change in the Maskan bank branches in the city of Tabriz at the significant level of $0 / 000,(\mathrm{P}<0 / 05)$ is $0 / 302$. As a result, at confidence level of $95 \%$, there is a significant positive correlation between the two variables. In other words, the effectiveness of job rotation on employees' readiness for organizational change in the Maskan bank branches in the city of Tabriz is 0/302.

After the test by Pearson correlation, regression analysis was performed at the level of $5 \%$. The results of the survey is presented in Table 8.

Table 8: Results of the survey

\begin{tabular}{|c|c|c|c|c|}
\hline Variable & $\boldsymbol{\beta}$ & $\mathrm{T}$ & Sig & Result \\
\hline Intercept & $2 / 207$ & $12 / 129$ & $0 / 000$ & Confirmed \\
\hline Bilateral relationship & $0 / 190$ & $4 / 885$ & $0 / 000$ & Confirmed \\
\hline
\end{tabular}

The mathematical relationship between job rotation and its impact on employees' readiness:

$$
\mathrm{Y}=2.207+0.19 \mathrm{X}
$$

It can be stated that one unit increase in job rotation leads to $0 / 190$ unit increase on employees' readiness, so it can be concluded that the regression model is statistically significant. 


\section{CONCLUSION}

According to the results related to the first hypothesis, it can be concluded that effectiveness of job rotation system among the employees is above average.

According to the results related to the second hypothesis, it can be concluded that employees' readiness for organizational change is above average

According to the results related to the third hypothesis, it can be concluded that there is a significant positive correlation between the two variables. In other words, the effectiveness of job rotation on employees' readiness for organizational change in the Maskan bank branches in the city of Tabriz is $0 / 302$. It can be stated from regression model that one unit increase in job rotation leads to 0/190 unit increase on employees' readiness, so it can be concluded that the regression model is statistically significant.

Research literature also indicates the influence of the effectiveness of job rotation system on employees' readiness for organizational change. As results of studies by Feyzian, Sarfarazkhan (2012), indicate a positive relationship between job rotation and participation and commitment in the work and a negative relationship to employees' motivation, which is in consistent with our research. The results of studies by Wistar El Jaya in 2013, suggests a correlation between change leadership and readiness for change with a commitment to change, which is in consistent with our research. The results of our research with the results of research by Susanto, 2008 are similar and both show that employees' readiness for change is important in the process of organizational change. Evaluation of the effectiveness of job rotation and its relation to organizational justice and organizational trust, by Pourghaz, Farhang and JamshidZehi in 2012 show that there is a significant correlation between the effectiveness of job rotation and organizational justice, organizational trust, the public trust and institutional trust, which is in consistent with our research, but there is no significant relationship with the horizontal trust and is not in line with this research. The results of studies by Jamalodin, Gohari and Falahdar (2012) as well Nasiri Pour, Raesi and Delpasand (2009) on the impact of job rotation on job performance, unlike the results of present study show no significant relationship between job rotation and employees' performance. 


\section{REFERENCES}

[1]Abili, Alikhani (2002). Performance Evaluation of human resource development at the School of Social and Behavioral Sciences Tehran University", Journal of Psychology, Issue 2, p. 57-76.

[2]Ayugh, Zandieh, M. (2009) A Model for job rotation scheduling with respect to costs of fatigue caused by jobs similarities through the development of genetic algorithms and colonial competition , Journal of Studies industrial management Issue 12, spring 89, P 29-54.

[3]Coyne, P. F. (2011) An evidence-based model of job rotation, A project submitted to Middlesex University in partial fulfilment of the requirements for the degree of Doctor of Professional Studies, School of Health and Social Sciences Middlesex University, 28th February 2011.PP.1-183.

[4] Dari and Akbari and Zandieh, (2012), "The two-objective scheduling and job rotation of multi-skilled employees through engineering approach", Studies in Management, Volume 17, Number 3, fall, 2013, p 1-21.

[5]Delpasand, and Raeisi, Bigdeli, Shahabi, (2010), "The impact of job rotation on job burnout at Kashani hospital in Tehran: A Case Study", Journal of Occupational Health, Volume 7, Number 4, winter 2010, p. 7-17.

[6]Farhang, Pourghaz, Jamshid Zehi, (2012), "The Effectiveness of job rotation and its relation to organizational justice and organizational trust", Public Management Research, Vol. VII, Issue 23, spring 2014, p $129-144$.

[7]Maleki and Gohari, Ghorbanian, (2012), "The relationship between structural empowerment and individual readiness to change," Journal of Occupational Care Research Center of Tehran University of Medical Sciences (Job Journal of Iran), Volume 25 , Issue 76, July 1391, p 10-18.

[8]Ortega, Jaime,(2001), " Job Rotation as a Learning Mechanism", Department of Business Administration, Universidad Carlos III de Madrid, 28903 Getafe, Madrid, Spain, jortega@emp.uc3m.es, 0025-1909/01/4710/1361\$5.00, 1526-5501 electronic ISSN, Management

Science (C) 2001 INFORMS, Vol.47, No.10, October 2001 pp.1361-1370.

[9]Paknejad, and Kargar, and Honari, (2010), "The relationship between learning organization and readiness for change in the Islamic Republic of Iran's Physical Education Organization" Sport Management Studies, Issue 12, Winter 1390, p. 168 -149.

[10] Rangriz, and Moradi, (2014), "organizational citizenship behavior and willingness to accept organizational change in the banking industry's ", Journal of Behavioral Sciences, p 65-96.

[11]Saravani, Shahin Rasouli \& Abbasi, Badri, (2013), " INVESTIGATING THE INFLUENCE OF JOB ROTATION ON PERFORMANCE BY CONSIDERING SKILL VARIATION AND JOB SATISFACYION OF BANK EMPLOYEES" , ISSN 1330-3651(Print), ISSN 1848-6339 (Online), UDC/UDK 331.101.262:[331.586:331.101.6, Tehnički vjesnik 20, 3(2013), ,PP. 473-478.

[12]Shah, Naimatullah, (2009), " Determinants of Employee Readiness for Organizational Change", A Thesis Submitted for the Degree of Doctor of Philosophy, Brunel Business School, Brunel University, West London, November 2009.

[13]Susanto, Alfonsus B, (2008), "Organizational Readiness for Change: A Case Study on Change Readiness in Manufacturing Company in Indonesia" BTS INTERNATIONAL JOURNAL OF MANAGEMENT PERSPECTIVES, ISSN: 1307-1629, 2008, 2(1), PP.50-62.

[14]Wageeh A. N., (2014). Do Job Rotation and Role Stress Affect Job Attitudes? A Study from Egyptian Context", University of Sadat City Menoufia, Egypt, American International Journal of Social Science, Vol. 3 No. 1; January 2014, PP.94-108

\section{Article history:}

- $\quad$ Received 10 March 2017

- Accepted 15 May 2017 